\title{
GLITCH SANATI
}

\author{
Sevtap KANAT ${ }^{1 *}$ \\ *Dr. Öğretim Üyesi, İnönü Üniversitesi, Güzel Sanatlar ve Tasarım Fakültesi, Grafik Tasarım Bölümü, \\ Malatya.
}

\begin{abstract}
Özet
Gelişen teknolojiyle birlikte sanatçı, sanat alanındaki bilgisinin yanında; sayısallaşan medya ve sürekli olarak değişen teknolojinin altyapısını da kavrayarak uygulamalarında kullanmaya başlamıştır. Bazen gelişen teknolojinin ürünleri olan dijital malzemelerde (Konsol,cd vb) görüntü, bozuk bir şekilde formunu kaybederek görünür. Dosyalarda veya görüntülerde oluşan bu hata, çakışma veya kodlarındaki değişim farkı görüntülerin ortaya çıkmasına sebep olur. Bilinçli veya bilinçsiz olarak bozuk medya ile oluşan işitsel ve görsel öğeler, göze hoş gelen yeni estetik sonuçlar meydana getirebilir. Bu bozulmalar ve kaymalar sürekli gelişim ve arayış içindeki sanatçıya esin kaynağı olarak sanatta tasarım boyutunda Glitch Art'ı meydana getirmiştir. Glitch Art, mükemmel olmayanın da estetik açıdan göze hoş gelebileceğini izleyiciye anlatmaya çalışır. Glitch Art, hem kullandığı materyal hem de uygulama teknikleri bakımından, ortaya koyduğu eser ve estetik anlayışıyla günümüze kadar ortaya çıkmış bütün sanat hareketlerinden daha farklı bir yere sahiptir. Bu çalışmanın amacı; gelişen teknolojiyle birlikte değişen dünyada sanatçının ve tasarımcının yeni görsel ürünleri anlamasına ve algılama da daha bilinçli hareket etmesini sağlamaktır.
\end{abstract}

Anahtar Kelimeler: Glitch, Glitch Sanat, Datamoshing, Databending

\section{GLITCH ART}

\section{Abstract}

Along with the developing technology, artists, as well as the knowledge of art, have gripped the digital media and the infrastructure of the technology, continuously changing, and begun to utilize them in their works. Images sometimes appear to be in a distorted form on digital products (console, CD, etc.), the products of the developing technology. This 'bug', overlap or code changes in files or images, results in different images to appear. The auditory and visual elements produced by the distorted media, consciously or unconsciously, can create new pleasing aesthetic results. These distortions and shifts have created Glitch Art in art design, as a source of inspiration for the artists who are on continuous quest of improvement. Glitch Art tries to explain the audience that what is not perfect can aesthetically be pleasing to the eye. Glitch Art, with its work and aesthetic understanding, has a different place than all art movements emerged up to the present day, both in terms of material and application techniques. The purpose of this study is to make the artists and designers understand new visual products in the context of the technology-driven changing world and behave more consciously in perception.

Keywords: Glitch, Glitch Art, Datamoshing, Databending

\section{Giriş}

Insanlar, fotoğraf makinası arkasından sinema ve televizyonun icadıyla, görsel-işitsel bir dünyanın içinde yaşamaktadır. Böyle bir ortamda sanatçı da yaşadığı dönemin teknolojisini, bilgi ve tecrübesiyle kaynaştırarak sanatına kendi yorumunu katmaktadır.

Teknolojik gelişmeye paralel olarak özellikle görsel iletişim ve tasarım alanında sanatçı tuval yerine monitörler, devreler; elle tutulabilir boya ve fırçaların yerine daha çok algoritma ve sayısal veriler üzerinde çalışmaktadır (Somer,2013: 1). Teknolojinin beraberinde getirdiği bazı hata oranları, dijital yanılsamalar görsel iletişim ve tasarım alanında farklı görsel uygulama alanlarının ortaya çıkmasına yardımcı olmuştur.

\footnotetext{
${ }^{1}$ Yazışma yapılacak yazar: sevtap.kanat@inonu.edu.tr
} 
Sanat, bazen bilinçli olarak bazen de bilinçsiz olarak yapılan bir uygulamanın sonucunda ortaya çıkmıştır (Atalay ve Kanat, 2017: 3475). Bu tür çalışmalar beraberinde geleneksel estetik algıyı da değiştirmiştir.

Somer'e göre "Medyanın fizikselden sayısala doğru geçişi ile beraber bu medyayı üreten makinelerin (bilgisayarlar, monitörler, yazıcılar vd. ) hızlıca yaygınlaşması ile artan hata sayısına cevap olarak Glitch sanat doğmuştur."(Somer,2013; Uslu, 2016). Glitch sözcüğü kayma (Pasek, 2017: 44), hata, kırıma ve bozukluk anlamlarına gelmektedir (Downey, 2014; Akıl, 2014; http://www.sanatatak.com/view/)

Bir hikâye ye göre, Bu terim ilk kez 1962 yılında Amerikan uzay programı sırasında Ingilizce olarak kaydedildi. Astronot John Glenn'in ilk önce "elektrik akımından gelen gerilimdeki bir artış veya değişim'i " tanımlamak için aksaklık terimini ortaya koyduğu iddia ediliyor (Uslu, 2016; Jackson, 2011; Moradi, 2004; Hugh S. Manon and Daniel Temkin, 2011 ). Ancak, bazı araştırmacılar bu terimin kayganlık anlamına gelen bir Yidiş dünyası, kayma ya da glitschig anlamına gelen Alman kelimesi gleiten'den türediğini iddia ederler (Jackson, 2011: 25). Evrimsel Sanatta yeni bir temsil olarak glitch sanatı, dijital sanatın yeni bir şekli ve dijital görüntülerini alışılmamış şekillerde değiştirerek dijital görüntüleri manipüle eden çeşitli teknikler için bir şemsiye terim olarak düşünülebilir (Heijer, 2013: 1). Glitch sanatı, genellikle çeşitli teknolojik hatalar sonucu veya çok sık olarak parçalanmış, solmuş sistematize edilmiş görseller olarak tanımlanabilir (Sotiraki, 2014: 19).

Metin ve imgenin fazlalığı hem sınırları içinde hem de dışında Glitch sanatının etkilerinin ve amaçlarının farklı yorumlanmasına yol açmıştır. Legacy Russell, glitch "gerçek" ve "sanal" öznelliklerin ikilik prensibi karşılığı aracılığıyla kendini beden meteforlarına ödünç verme ve feminist manifestosunun konusudur diye ifade eder. Sanatçı ve eleştirmen Rob Myer göre, glitch "önceki idealize edilmiş sosyal ve estetik bir düzenden" kopma çabası içinde gürültünün fetişistik bir dönüşümüdür. Ses küratörü Caleb Kelly benzer bir şekilde; aşırı derecede biçimlendirilmiş sosyal ve estetik kanallar gürültüyü 20.yüzyılın deneysel müzik ve avangart sanatının zengin kapsamlı bir projesi olarak glitch'i görür. Diğer taraftan kültürel kuramcı Greg Hainge veri bozulmasının "olgucu estetik etkinin" ötesine bakan teknolojik başarısızlıkta insan makine işbirliği unsurlar için mümkün olduğu kadar derinine inmek en fazla glitch'in iddiasıdır (Pasek, 2017: 45). Birezilya'lı glitch sanatçısı Sabato Visconti, Glitch'i karakteristik olarak "glitch, dikkatlice arızanın benzetmesidir. O bazı incelikler gerektiren anlamsız bir tasarıdır çünkü bazı glitch'ler bozuk bir dosyanın tanımlanmasının ötesinde ve diğer aksaklıklar hiçbir etkiye sahip olmayacak" şeklinde ifade eder (Sotiraki, 2014: 19).

Aslında günlük hayatımızda pek çok alanda karşımıza çıkan Glitch (aksaklıklar) bizler için yeni bir şey değil örneğin; televizyonda yaşanan frekans sorunları, yayındaki iletişim aksaklıkları, CD de oluşan takılmalar, sesli ve/veya görüntülü internet görüşmelerindeki bağlantı sorunları olarak karşımıza çıkmaktadır. Fakat sanatçı farklı olarak bu aksaklıkları sanatı için bir malzeme hâline getiriyor ve estetik bir tavra dönüşüyor.

Kaçtıoğlu, bozulmalar adlı sergisinde çalışmaları hakkında bilgi verirken "Bir televizyon programını bozuk bir antenle izlediğimizde televizyondan kulağı rahatsız eden bir sesin yanında, görsel kaymaların ve bozulmaların ortaya çıktığını görürüz. Bu noktadan sonra ne anladığımızın veya ne gördüğümüzün artık bir önemi kalmamış; algı, objektiflikten sürüklenerek bir macera yoluna koyulmuştur. Her bir ses, her bir görüntü zaman bağlamından koparılarak farklı bir evrende yorumlanmaya hazır hale gelmiştir." sözleriyle Glitch sanatını açıklamıştır (Uslu 2016: 1970).

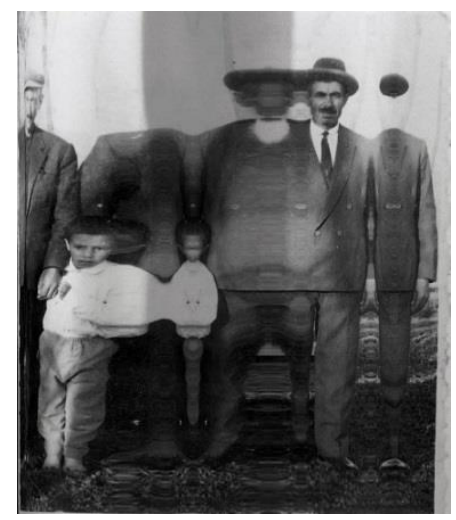

Resim 1. Kaçtıoğlu, Kübra 
Kısacası glitch sanatı, önceden rastlantısal olarak teknik anlamda bir arıza ve aksaklık sonucu oluşan görüntülerin daha sonra sanatçıların kendi yorumları ile estetik bir değer katarak yaptıkları görsel manipülasyonlardır (uslu,2017: 64; Choi \&Ahn, 2017:2). Daha çok elektronik ortamdaki yazılım dilinde oluşan bir hatanın sonucu ekrana yansıyan bozulmuş görüntünün (resim veya videoda) veya ses hatasının kullanıldığı glitch sanatında, bir düzensizlik veya komposizyonsuzluk söz konusu değildir.

Glitch sanatı her zaman rastlantı ve hata sonucu oluşmuş bir sanat değildir (Downey,2014:1). Tam tersine yapısı bozulmuş bir görüntünün yarattığı rastlantısallığın farklı sanatsal kompozisyonlar sunabilmesidir. Glitch sanatçısı aksaklık sanatının görsel ifadesini yakalamak için spontan aksaklıkları korumak taraftarıdır (Jackson,62;).

Sanat döneminin toplum yapısının, sosyolojisinin birer yansımasıdır. Glitch sanatı da teknoloji çağında hayatın içinden anlamlar taşır.

Sanatçılar bu tür manipülasyon çalışmalarını aksaklık sanatı, fotoğrafta dijital sürrealizm (Uslu, 2017: 68), bellek kaymaları, görüntü algoritması, uyumsuz kaos gibi farklı farklı isimlerle ifade etmişlerdir. İsimler farklıda olsa her sanatçı Glitch sanatına katkıda bulunmuştur.

Glitch sanatçısı ve akademisyen olan Rosa Menkman tarafından 2010 yılında kaleme alınan Glitch sanatı manifestosunda bu sanatın teknik kaynağını, konumunu ve felsefesini ortaya koymaktadır. Teknolojinin mükemmelliğine dair söylemleri dışlayıp insan yapımının önemini vurgulamakta ayrıca hatanın sıra dışı estetiğini ortaya koymaktadır.

Menkman: "Glitch'i bir nesneyi sıradan biçimden ve söyleminden anlamının yok olduğu bir yıkıma doğru kaydıran harika bir müdahale olarak deneyimliyorum." Sözleriyle glitch sanatının geleneksel sanat anlayışını sorgulatan özelliğine vurgu yapmaktadır. Anlamları yeniden sorgulamak eylemi her dönemde ve bütün sanatlarda mevcut. Fakat Menkmana göre glitch sanatında bu daha da ileri giderek, durağan hiçbir formun kullanılmaması bu sanatın en önemli özelliği olmuştur(Akıl,2014).

Glitch'in, "Glitche uygun (Appropriated), Kazara (Accidental), Tesadüfen (Coincidental), Bulunmuş (Found), Gerçek (Real), Bilerek (Deliberate), Planlanmış (Planned), Tasarlanmış (Designed), Yapay (Artificial)" (Somer, 2013:3)şeklinde sınıflandırması yapılırken Glitch sanatta eser üretiminde ise iki kavramla karşılaşıyoruz; Datamoshing ve Databending.

Bunlardan ilki Datamoshing (Veri Kısıtlama), sıkıştırılmış video görüntülerinde kullanılan sıkıştırma ve çözme algoritmaları üzerinde değişiklik yaparak yeni bir imaj veya yeni video görüntüleri elde etmeye denir. Databending ve Circuitbending kavramları ise aslına sadık kalınarak daha önceden var olan veriyi veya 0 veriyi farklı programlar kullanarak anlık üreten devreyi değiştirme işlemidir. Bu değişiklikler anı dosya formatında kaydedilir. Databending'den farklı olarak Circuitbending kavramının özelliği daha önceden hazırlanmamış anlık elde edilen, işlenen verinin veya sinyalin üretildiği devreler üzerine müdahalede bulunarak hasarlı ve bozuk veriler elde edilmesidir. Circuitbending daha çok elektronik müzik ekipmanlarında kullanılan bir tekniktir (Somer, 2013:2-3).

Iman Moradi, Glitch sanatının saf glitch (aksaklık) ve glitch-alike (aksaklık) benzeri şeklinde iki formunu tanımlar (Moradi, 2004; Jackson, 2011). Saf glitch sanatçıları aksaklığın görsel ifadesini serbest yani direkt olarak sergileyerek ve depolayarak çalışmalarını üretirler. Glitch benzeri olarak bilinen sanatçılar ise sanatsal bir çalışma elde etmek için aksaklıkları kendi üretir. Saf glitch sanatçıları bu istenmeden olan anlık saf aksaklıkları yakalayabilir ve onları web sitelerine yükleyebilir fakat bu yakaladıkları spontan aksaklık anları geçicidir. Glitch benzeri sanatçıları ise farklı olarak databending olarak bilinen yazılım ve donanım manipülasyonları kullanarak çalışmalarını üretir (Jackson, 2011: 62).

İnsanoğlu, sanayi devrimiyle başlayan dijital çağda internet ve sosyal medya araçlarının gelişimiyle gerçeklik yok olurken sahip olmaya başladıkları dijital ifade yöntemleri ile sanal bir dünyada dijital kimlikler kazanmaktadırlar.

Teknolojik gelişmeler ile beraber hayatımıza giren akıllı cep telefonlar ve bu telefonlardaki kameralar ile çevremizdeki öğeleri son derece başarılı bir şekilde sayısallaştırma ve gerçeğe en yakın bir şekilde görseller elde edilebilmektedir. Fakat kullanıcılar bunun tam tersine fotoğraf çekiminin ardından teknolojinin sunduğu filtreleri kullanarak ışık ve renk öğelerinin bozulmasını sağlarlar. Kullanıcılar daha kusurlu ve hatalı 
sistemlerin çıktılarını beğenerek sosyal medyada kullanmaktadırlar. Bu da insanların estetik algılarının mükemmeliyetçi olmadığını ortaya çıkarmaktadır. İnsanların estetik algılarının da zamana göre değişebileceğini görmektedir. Estetik algıdaki bu değişim Glitch sanatının başarısının temeli de olabilir.

Glitch sanatı insanların güzel, estetik ve doğru olarak bilineni sorgulamalarını sağlıyor. Fakat sahip olduğu o yıkıcı tavır öncekini bozup ortaya yeni bir yapıt çıkmasına sebep oluyor ve ortaya çıkan iş eskisinden tamamen bağımsız bir anlam taşıyor.

Bu yıkıcı tavrı açıklamada en iyi örnek Luziano Testi Paul'un 2003 tarihli "JPEGged Mona Lisa" adlı işidir. Paul, Da Vinci'nin "Mona Lisa" resmini manipüle ederek onu bambaşka bir görselliğe dönüştürür. Eser sanatçının müdahalesi sonucu yepyeni bir anlama ve yapıya bürünmüştür. Yatay bir katmanda pikselleştirilen ve renkleri bambaşka tonlarla manipüle edilen bu işte, müdahalesiz bırakılmış tek küçük bir alan figürün gözlerinin olduğu bölümdür. Sadece bu bölge bize çalışmanın orijinalini hatırlatsa da eser artık yepyeni ve bambaşka bir anlatı hâline gelir. Artık eski orijinal eserin seyirciye verdiği huzurda kalmamıştır (Destici,2016).

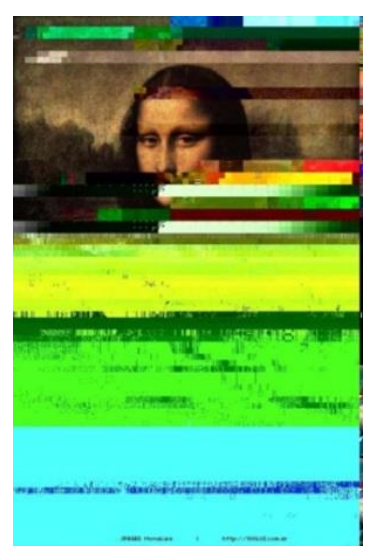

Resim 2. Luziano Testi Paul, “JPEGged Mona Lisa”, 2003

Popüler kültürün ve görsel medyanın önemli alanlarından biri olan sinema sektöründe ise Glitch sanatının özellikle bilimkurgu alanında kullanıldığını görürüz. (Somer, 2013: 5) Günümüzde sinema endüstrisinin yanında video oyun endüstrisi de önemli bir sektör haline gelmiştir. Bu oyunların tasarım aşamasının tamamında veya belli bölümlerinde Glitch sanatı kullanılarak hazırlanmaktadır.

Glitch sanatı görsel medya dışında işitsel medyada ve görsel ve işitsel medyanın bir arada kullanıldığı müzik kliplerinde de kullanılmıştır (Somer, 2013:6).

Müzikte de aynı şekilde glitch uygulamaları yapılmakta ve bu müziğe de glitch müzik denilmektedir. Glitch sanat ve müzik, görsel sanatlar, müzik, animasyon ve hatta edebiyat gibi çeşitli kültür endüstrilerinde kullanılmaktadır. Yapay yaşam sanatı ve evrimsel sanat aksaklık sanatını ve müziğini yaratığına dair yeni araştırmalar başlamıştır. Son zamanlarda, evrimsel sanatı kullanarak aksaklık eserleri yaratmak için bir teknik önerilmiş. Bu teknikte genetik programlama ve özel operatörler kullanarak aksaklık eserleri üretilmektedir. Daha spesifik olarak, aksaklık sanatı için bir genotip geliştirdi ve bu başlatma, seçim, geçiş ve mutasyon operatörleri. Bu çalışmalar, yüksek düzeyde bir aksaklık yapısının yaratılabileceğini göstermiştir. Resim 3, evrimsel sanata dayalı bazı aksaklık resimlerini göstermektedir. (Choia, \& Ahn, 2017:2). 


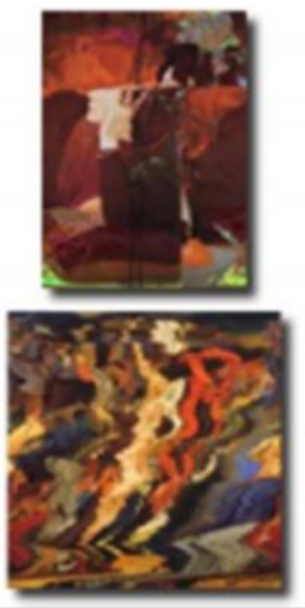

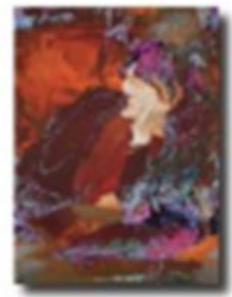
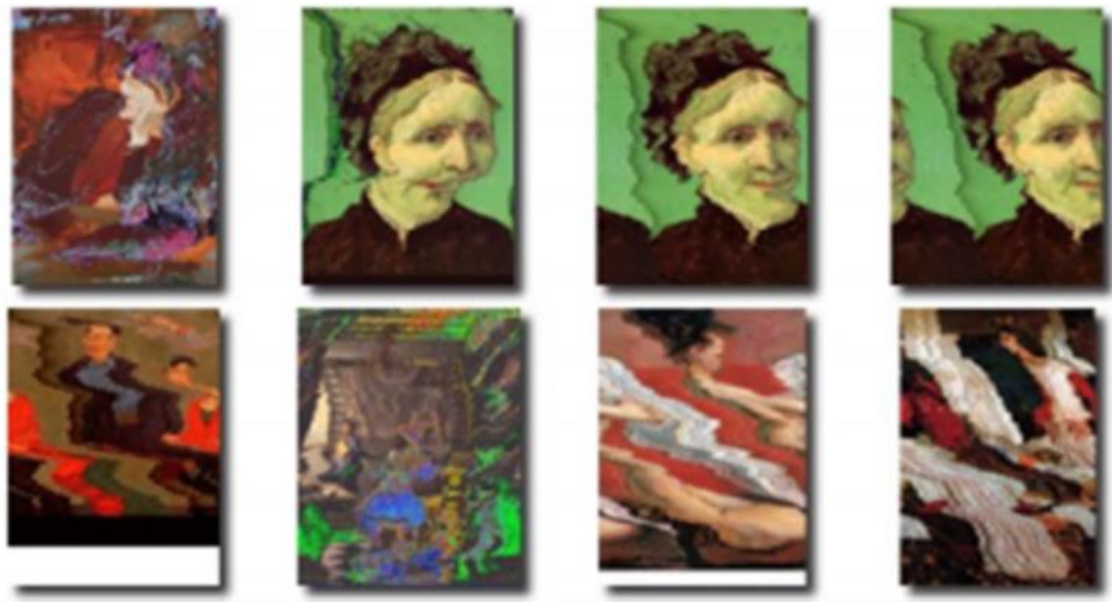

Resim 3. Evrimsel sanata dayalı bazı aksaklık resimleri.

Glitch sanat ve evrimsel sanat, birtakım benzerlikleri paylaşır. Her ikisi de bir tür "üret ve test et" paradigmasını kullanır, bu sayede bir yazılım programı bir dizi olasılık üretir ve bir sanatçı ya da bir yazılım bileşeni tarafından bir seçim yapılır. Manon ve diğerleri, bir aksaklık imgesi oluşturamadığını, sadece bir aksaklığı tetikleyebildiğini ve aksaklık sanatının bu uçucu yapısının, onu sözde-sanat eseri bir sanat biçimi haline getirdiğini belirtir. Bir görüntüye bir aksaklık işlemi uygulamak çok basittir, ancak ilginç görsel içerik oluşturmak çok önemlidir. Glitch ile ilgi çekici görsel içerik bulmak her ne kadar farklı olsa da, hiçbir şekilde rastgele bir süreç değildir. Aynı görüntüdeki aynı hata işlemlerinin uygulanması aynı son görüntüye neden olacaktır (Heijer,2013: 3).

\section{GLITCH SANATÇILARI VE ÇALIŞMALARI}

Glitch sanat alanında aktif olarak üretim yapan sanatçılara ülkemizden İnteraktif enstalasyonlar üreten Ozan Türkkan'ın çalışmaları (Resim, 3) örnek olarak gösterilebilir. Çalışmalarında Glitch sanat öğeleri kullanılarak gürültü müziğini görselleştirmeye çalışmıştır. Sanatçı eserlerini sergilerken aynı anda izleyiciyi de aktif etmekte ve dinledikleri seslerin görsel çıktılarını deneyimleme fırsatını tanımaktadır.

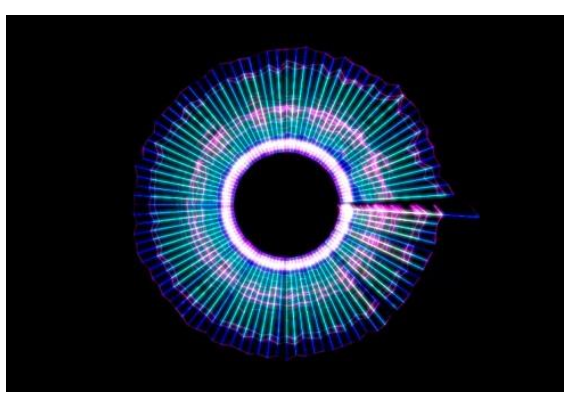

Resim 4: Ozan Türkkan 'Micro Flow Cube' isimli video

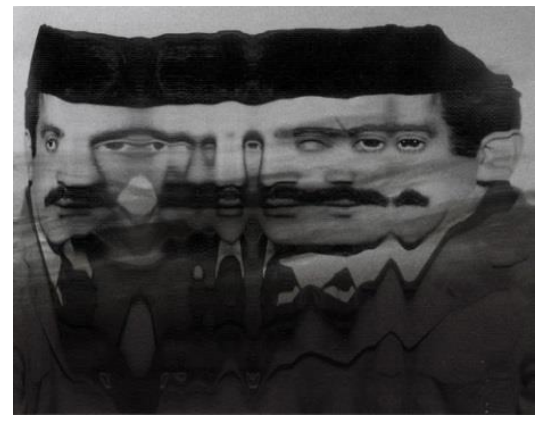

Resim 5. Kübra Kaçtıoğlu

Ülkemizde bu alanda çalışan bir diğer sanatçı da Kübra Kaçtıoğlu'dur. Fotoğraf ve sinema tutkunu olan Kübra Kaçtıoğlu'nun çalışmaları (Resim 5 )'uyumlu aykırılık’ şeklinde tanımlanmaktadır. Sanatçı izlenimlerinin fotoğraf ve manipülasyon aracılığıyla somuta aktarmaya çalışır. Görünen gerçeği bire bir yansıtmak yerine soyutlamayı tercih etmektedir. Gerçekliği kendi etrafında döndürerek yorumlama eğilimi hemen hemen tüm çalışmalarında görülmektedir. Özellikle de sanatçının son dönemlerde yapmış olduğu "Distortion, relation" adlı eserlerinde yoğun bir şekilde algılanmaktadır. Çalışmalarında grup halinde çekilmiş eski fotoğrafları kullanmış ve bu fotoğraftaki görüntüleri eğip bükerek bir dalgalanma hissi yaratmıştır. 


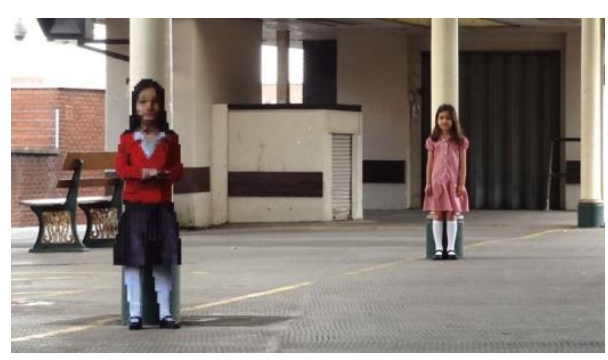

Resim6: Luke Jerram, Maya, 2013

Glitch sanatıyla ilgilenen diğer bir sanatçıda Luke Jerram. Sanatçının en ünlü eserlerinden biri "Maya" adlı çalışmasıdır. Sanatçı, dijital çağın küçük yaştan başlayarak herkesi kendi sanal gerçekliğine hapsettiğini anlatan gerçekçi bir modelin düşük çözünürlükteki heykeli olan "Maya" adlı çalışmasını (Resim 6) 2013-2015 yılları arasında İngiltere deki Bristol Temple Meads istasyonunda 1. Platformda izleyiciye sunmuştur.

Bu proje (Maya) Jerram'ın devam eden görsel algı ve optik yanılsama araştırmasından doğmuştur. Renk körü olduğu gerçeği, ona "algının kenarlarını" keşfetmeye doğal bir ilgi göstermesine sebep oldu.

Maya, üç boyutlu, pikselli bir portre gibi hareket eden heykeldir. Yoğun pikselli karelerden oluşan iki boyutlu bir görüntü belli bir mesafeden heykel kolaylıkla okunabilir. İzleyici yaklaştıkça, nesne küplere bölünmüş gibi görünmekte.

Dijital çağ hakkında Luke Jerram "Kızım Maya 3 yaşından beri iPhone kullanabilmekte. Onun için teknoloji, bir kalem gibi, kullanılacak günlük bir alet gibiydi. O bu teknolojik dünyaya doğdu ve onun için dijital devrim ve teknolojik gelişimin hızı henüz belli değil. " sözleriyle insanları kuşatan, teknolojinin baş döndüren hızını anlatmaya çalışmıştır (https://www.lukejerram.com/maya/).

Diğer bir sanatçıda Peter Norby, Trapcode adlı grafik şirketinin Kurucusudur. Peder Norby, dünya genelindeki lokasyonlardan topladığı 45 adet ekran görüntüsünü "mapglitch" adlı çalışmasında kullanmıştır (Somer, 2013.4).

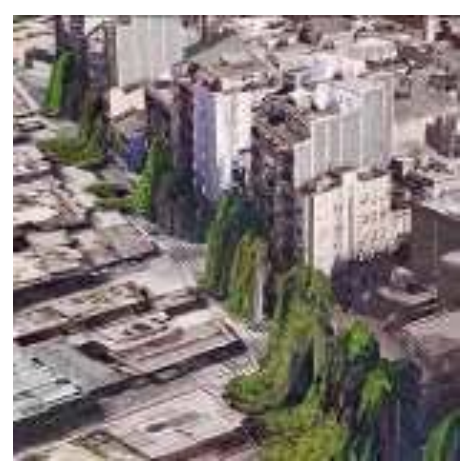

Resim 7. Peder Norby, Ağaç fırlatan evler, Barselona, 2013

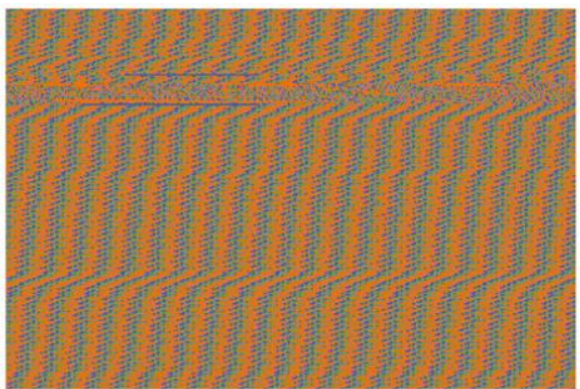

Resim 8: Ant Scott 
Ant Scott Glitch sanat hareketinin babası olarak iddia edilmektedir. 2002'den beri saf glitch'in öncüsü. Onun çalışmaları glitch benzeri ve saf glitch arasındadır. Scott saf glitch parçalarının çoğunu yazılım ve donanım aksaklıklarından sağlar. Scott'ın data-bending ile yarattığı görüntüler glitch benzeri çalışmalardır. Çalışmasının çoğunluğu kişisel bilgisayarında bozuk dosyalardan kaynaklanıyor. Binary kodları kare veya dikdörtgen bloklar halinde görünecek şekilde piksellere çevirme, Scott çalışmalarında geleneksel ve kişisel bilgisayar monitör alanı boyutlarında çalışır (Jackson, 2011: 65).

Glitch sanatıyla ilgilenen sanatçılardan bazıları: Nick Briz, Rosa Menkman, Luis Sierra, Andy Denzler, Hugh Manon, Mishka Henner.

\section{SONUÇ}

Günümüz dijital çağda teknolojideki gelişim, çevremizi çok yoğun bir şekilde kuşatmaktadır. Bu dönemde icat edilmiş birçok teknolojik araçlar ile farklı tarz ve teknikte sanat eserleri üretilmiştir. İnsan eliyle tasarlanan teknoloji ve sayısallaşmayla beraber üretilen elektronik cihazlar, yeni yazııımlar yaşamımızın kalitesini artırırken bazen de sistemden kaynaklanan hatalarda oluşabilmektedir. Glitch sanatçıları her zaman bu hatalardan beslenmesini bilmiştir. Bunun sonucunda yenilikçi, sorgulayıcı farklı tarz ve teknikte sanat ürünlerinin ortaya çıkmasını sağlamıştır. Bu eserler, insanlar tarafından güzel, estetik ve doğru olarak kabul edilenleri sorgulamalarına neden olmuştur. Glitch sanatının bu yıkıcı tavrıyla, eskisinden tamamen bağımsız bir anlam taşıyan yeni işler ortaya çıkarılıyor. Glitch Art, kullandığı materyal ve uygulama teknikleri bakımından günümüze kadar ortaya çıkmış bütün sanat hareketlerinden daha farklı bir yere sahiptir.

Sanattaki bu yeni arayışlar beraberinde neyin sanat olup olmadığı tartışmalarını da getirmiştir. Sanatçı her dönemde olduğu gibi arayarak, deneyerek aynı zamanda yaşadığı dönemin teknolojik imkânlarını da kullanarak düşüncelerini, duygularını ve çevresini yorumlamıştır. Sanatçılar farkındalıklar yaratarak, güncel sanatsal ürünler ortaya koyarak anlama ve algılamada bilinçli hareketliliği doğurmaya çalışmışlardır.

\section{Kaynaklar}

1.Akıl, Selman Hatanın Estetiği Olarak Glitch Sanatı, http://www.sanatatak.com/view/hatanin-estetigi-olarakglitch-sanati adresinde 26.10.2018tarihinde indirilmiştir.

2. Atalay, Mustafa Cevat ve Kanat, Sevtap (2017). Görsel Sanatlarda Rastlantı Ve Yaratıma Etkisi, İdil Sanat ve Dil Dergisi, 2017, Cilt 6, Sayı 39, s:3475-3500.

3. Choia, Tae Jong \& Ahn, Chang Wook (2017). Artificial life based on boids model and evolutionary chaotic neural networks for creating artworks, Swarm and Evolutionary Computation, 06.11.2018 tarihinde https://www.sciencedirect.com/ adresinden indirilmiştir.

4. Destici, Orkun (2016). Bozarak Yapmak: Glitch, https://manifold.press/bozarak-yapmak-glitch. 02.11.2018 tarihinde alınmıştır.

5. D o w n ey, J o n as (2014) G L I T C H AR T, https://jonas.do/assets/essays/glitch-art-jonasdowney adresinden 30.10. 2018 tarihinde alınmıştır.

6. Heijer, Eelco Den (2013). Evolving Glitch Art, 30.10. 2018 tarihinde https://www.researchgate.net/publication/253650085 adresinden alınmıştır.

7. Jackson, Rebecca (2011). The Glitch Aesthetic, Thesis, Department of Communication, Georgia State University.

8. Kaçtıoğlu , Kübra Bozulmalar 26.10.2018 tarihinde https://www.dadatart.com/2014/01/14/kubra-kactioglubozulmalar adresinden indirilmiştir.

9. Manon, Hugh S and Temkin, Daniel (2011).Notes on glitch. World Picture 6, winter, 13.11.2018 tarihinde http://worldpicturejournal.com/WP 6/Manon.html adresinden alınmıştır.

10. Moradi, Iman (2004). Glitch Aesthetics, 26.10.2018 tarihinde http://www.organised.info/wpcontent/uploads/2016/08/Moradi-Iman-2004-Glitch-Aesthetics adresinden indirilmiştir. 
11. Pasek, Anne (2017). The Pencil of Error: Glitch Aesthetics and Post- Liquid Intelligence, Photography and Culture, Volume 10, Issue 1, March, pp. 37-52.

12. Somer, Hasan Sarp (2013). Sayısal Medya Sanatı Olarak Glıtch Sanatı Ve Etkileri, 26. 10. 2018 tarihinde https://ecitydoc.com/download/makale-sayisal-mmar- adresinden indirilmiştir.

13. Sotiraki, Virginia (2014). Glitch Art Narratives, An investigation of the relation between noise and meaning, A Master's Thesis for the Degree Master of Arts (Two Years) in Visual Culture, Division of Art History and Visual Studies Department of Arts and Cultural Sciences, Lund University.

14. Uslu, Yaşar(2017). Grafik Tasarımda Mükemmellik Kusurluluk Afişler, Ekin Yayınları: Bursa.

15. Uslu, Yaşar(2016). Görsel Bozulmanın Adı; Glitch Art, İdil Sanat ve Dil Dergisi, Cilt 5, Sayı 27, s: 1967 1976.

\section{GÖRSELLER}

Resim 4: Ozan Türkkan 'Micro Flow Cube' isimli video, 02.11.2018 tarihinde http://www.artfulliving.com.tr/sanat/alternatif-bir-galeride-alternatif-bir-sergi-i-955 adresinden alınmıștır.

Resim 1 ve Resim 5 . Kaçtıoğlu, Kübra 02.11.2018 tarihinde (https://www.dadatart.com/2014/01/14/kubrakactioglu-bozulmalar adresinden alınmıştır.

Resim 2. Luziano Testi Paul, "JPEGged Mona Lisa", 2003, 26.10.2018 tarihinde https://manifold.press/bozarak-yapmak-glitch adresinden alınmıştır.

Resim 3: Evrimsel sanata dayalı bazı aksaklık resimleri 06.11.2018 tarihinde https://www.sciencedirect.com/ Choia, Tae Jong \& Ahn, Chang Wook (2017). Artificial life based on boids model and evolutionary chaotic neural networks for creating artworks, Swarm and Evolutionary Computation dergisindenn alınmıştır.

Resim 6: Luke Jerram, Maya, 2013, 26. 10. 2018 tarihinde https://www.lukejerram.com/maya/ adresinden alınmıştır.

Resim 7. Peder Norby, Ağaç fırlatan evler, Barselona,2013, 26. 10. 2018 tarihinde https://www.google.com.tr/search?q=Peder+Norby adresinden alınmıştır.

Resim 8: Ant Scott , 13.11.2018 tarihinde https://scholarworks.gsu.edu/communication theses/80/ adresinden alınmıştır. 